\title{
Cuerpo, EMOCIONES Y EDUCACIÓN EN TIEMPOS DE PANDEMIA
}

Adriana Yamile Suárez ${ }^{1}$ Sandra Maritza Moreno

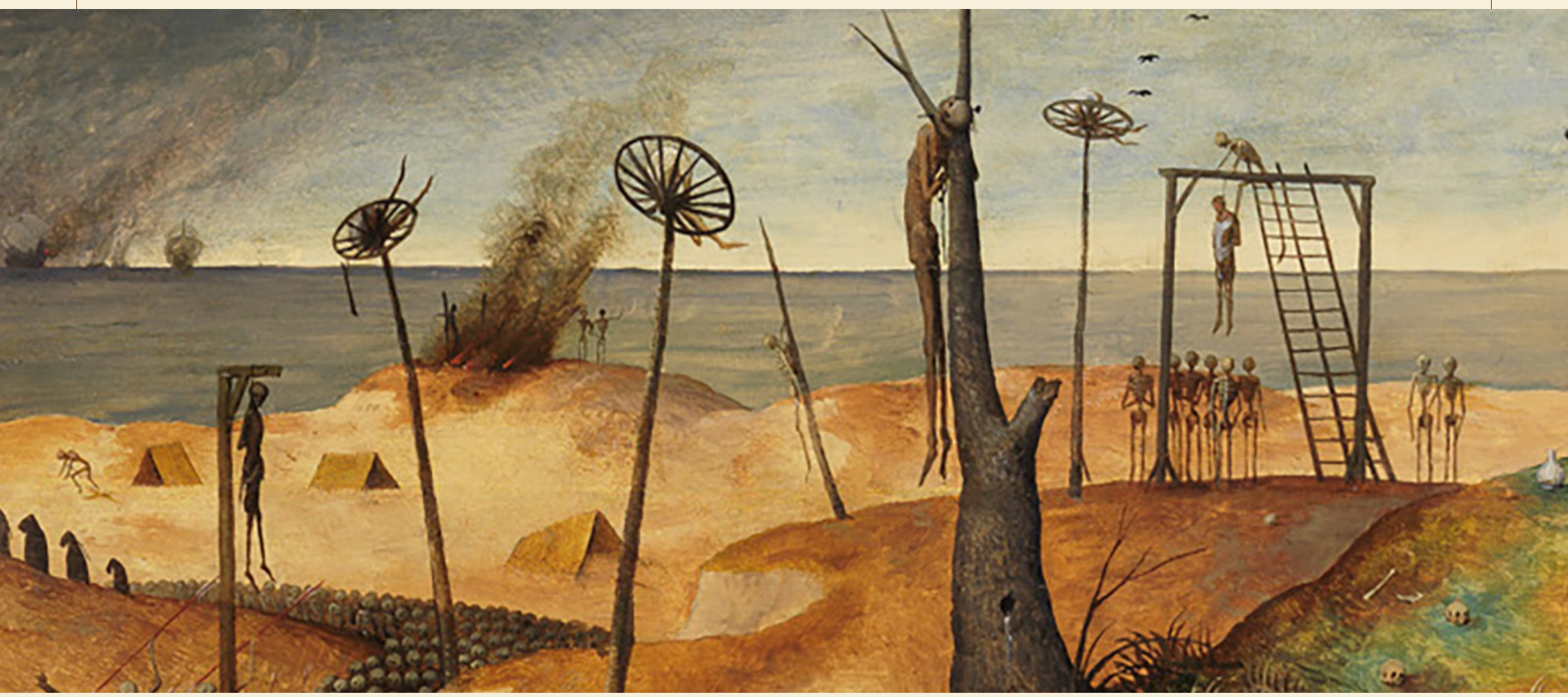

1 Magíster en Lingüística Española del Instituto Caro y Cuervo. Profesora catedrática de la Maestría en Pedagogía de la Lengua Materna de la Universidad Distrital Francisco José de Caldas. Docente investigadora del Grupo Lenguaje, Cultura e Identidad. Investigadora Junior (Convocatoria 833-2018, Minciencias). Correo electrónico: aysuarezr@udistrital.edu.co ORCID https://orcid.org/0000-0002-1728-3882

2 Magíster en Educación de la Pontificia Universidad Javeriana. Doctoranda en Educación, Universidad Santo Tomás. Coordinadora académica del Gimnasio Moderno. Profesora catedrática de la Maestría en Pedagogía de la Lengua Materna de la Universidad Distrital Francisco José de Caldas. Docente investigadora del Grupo Lenguaje, Cultura e Identidad. Correo electrónico: sammorenoc@udistrital.edu.co ORCID https://orcid.org/0000-0003-4800-2083

Cómo citar: Suárez, A. Y., Moreno, S. M. (2020). Cuerpo, emociones y educación en tiempos de pandemia. Enunciación, 25(2, separata), XXVI-XXX. https://doi.org/10.14483/22486798.17021 

1 siglo XXI se ha encargado de convertir la historia en piezas de un espectáculo al que asistimos diariamente. Las guerras, las masacres, los desplazamientos, los campos deforestados, las quemas indiscriminadas de la selva se transmiten en vivo y en directo; $\sin$ embargo, aparecen en las pantallas de los espectadores como hechos ajenos, como cintas de películas que se repiten. En este universo de información inmediata, la pandemia de 2020 ha revelado la condición de vulnerabilidad del ser humano y nos la ha repetido hasta el vértigo pues nos anuncia lo que todos, como especie, estamos viviendo.

Minuto a minuto la información salta por cada recodo. En los celulares, en los ordenadores, en los diarios y hasta en los memes, se construyen sus narrativas y se multiplican de manera vertiginosa. Pero es curioso que estas historias estén hechas más de datos, números de contagios, muertes, recuperados y análisis estadísticos. Allí los sujetos y sus relatos no aparecen. Ese retrato de nuestro espíritu nos espanta, por eso, anhelamos con ahínco los encuentros, las palabras, los abrazos, como una forma de recuperar la esencia extraviada.

Antes de esta pandemia, la expresión de las emociones se daba no solo a través de las palabras sino también a través del contacto físico: un abrazo, una caricia, un gesto. Pero ahora estas manifestaciones están restringidas y la escasez de ese contacto hace que quizás las palabras y las acciones tengan mayor fuerza en las interacciones cotidianas. Esta situación de confinamiento ha conllevado la resignificación de muchas de las prácticas sociales. Ir al cine, tomar un café con los amigos, celebrar un cumpleaños, conmemorar nuestros muertos, entre otras, perdieron su aparente naturalización y con la llegada del virus empezó su proceso de extrañamiento. Entiéndase este último en una doble vía: se extraña en términos de su ausencia y se extraña en el sentido de ser objeto de análisis en cuanto se perciben estas acciones de otras maneras.
Asimismo, el escenario educativo, como parte de la cotidianidad, también se vio impactado. Los encuentros presenciales cara a cara, caracterizados por la interacción in situ y la posibilidad de compartir con otros en la esfera pública, transitaron hacia los encuentros remotos (sincrónicos o asincrónicos), a la presencialidad asistida por tecnologías. Es curioso cómo el adjetivo remoto invita a pensar en sus dos acepciones: por un lado, lo que se encuentra a cierta distancia, retirado, alejado, y por otra, aquello que resulta inverosímil y que es muy poco probable que suceda. Las pantallas conectan con la voz, pero algo seguimos extrañando, algo nos es ajeno. La presencia del otro se escapa, los rostros se convierten en siglas y, con suerte, en fotografías, por eso lo que parecía inverosímil, ocurrió.

En las clases en línea se encuentra una atmósfera extraña. Una situación traumática como la pandemia nos deja sometidos al silencio, nos despoja de las palabras propias, quizá por eso comentamos con curiosidad y énfasis con los colegas los largos silencios en las clases en línea que nos parecen aún más abrumadores, por eso la expresión: “¿me escuchan?, ¿están ahí?” es una de las más recurrentes en las clases. En los espacios presenciales, se lograba reconocer en las miradas, los gestos, en la cercanía del otro, formas de decir en el lenguaje donde se construía un contrato tácito. Esta pandemia ha hecho explorar nuevas formas para vivir en las aulas, pero, sobre todo, ha permitido volver sobre lo esencial: el sujeto y las palabras.

En consecuencia, la escuela se ha llevado a la esfera privada de las familias de estudiantes y docentes, y presupone cambios en los factores de orden cognitivo pues se debe repensar cómo se enseña y cómo se aprende en estos nuevos escenarios. Pero ¿qué pasa entonces con el cuerpo, las emociones y las palabras en esta pandemia? Más que dar respuesta a esta pregunta, lo que se pretende en estas líneas es reflexionar en torno a las relaciones cuerpo/emociones/ educación en tiempos de pandemia. 


\section{El cuerpo}

Desde sus inicios la ciencia cognitiva hizo uso de la metáfora del computador para explicar qué pasaba con la mente humana. A partir de esta premisa se pensó en la centralización de los procesos cognitivos en el cerebro y, en esa medida, se creía que el cuerpo en su totalidad no estaba ligado de una manera directa con la cognición o que aspectos como la percepción o la acción eran solamente elementos periféricos de estos procesos. No obstante, esta perspectiva de la cognición se puso en tensión al considerar algunas ideas del filósofo Merleau-Ponty (1975) para quien el cuerpo, la percepción y la interacción son claves para conocer el mundo. O los postulados de Jean Piaget (1999) en su psicología del desarrollo en donde el cuerpo toma un papel importante. Años más adelante estas ideas dieron lugar, en parte, a la teoría que se conoce hoy como cognición encarnada o corporizada (embodied cognition), la cual considera que la cognición emerge a través de la experiencia del cuerpo. Dicho de otro modo, la percepción y la acción que antes eran solamente vías para alimentar la cognición son vistas como cognición en sí mismas (Varela, Thompson y Rosch, 1993).

En ese sentido, si la cognición corporizada considera que muchos aspectos de la adquisición y uso del conocimiento dependen del cuerpo físico en su totalidad y no solo del cerebro, ¿qué pasa entonces con el cuerpo en los procesos educativos en tiempos de pandemia y confinamiento? Las personas se circunscriben -con suerte- a un metro cuadrado durante largas jornadas frente a la pantalla de computador o un celular. Por otro lado, las falencias asociadas a la baja calidad en términos de conectividad hacen que en videollamadas y videoconferencias se desactiven las cámaras para no morir en el intento comunicativo. Entonces, la quietud del cuerpo y la falta de contacto visual se convierten en un problema que incide en el ambiente de aprendizaje, en lo relacionado con los recursos de la comunicación no verbal.

A partir de los estudios de McNeill (1992), se afirma que los gestos facilitan la comunicación y hacen posible también el procesamiento del lenguaje. Tener la oportunidad de ver al otro permite el reconocimiento de los interlocutores y posibilita las adecuaciones discursivas en función de la comprensión. Por ejemplo, si se está en el cara a cara, ver y reconocer al otro hace que se pueda situar el clima del aula, evaluar en la acción, reorientar la práctica. En ese mismo marco, con el descubrimiento de las neuronas espejo (Gallese, Fadiga, Fogassi y Rizzolatti, 1996), se sabe que estas se activan cuando se realizan acciones y cuando se ve a otros realizarlas. Este descubrimiento da cuenta de un sustrato neurológico que está presente en los canales de comunicación, específicamente aquellos que conectan las acciones previamente observadas y su posterior realización. Pero, al no poder vernos, hemos sentido extrañeza o agotamiento al tratar de explicar un tema o de seguir una conversación cuando no se puede ver al interlocutor.

En ese sentido, la educación en tiempos de pandemia tendrá que repensar y analizar el papel del cuerpo para usarlo, actuar con él, puesto que es con el cuerpo como comprendemos y habitamos el mundo.

\section{Las emociones}

La situación de la pandemia ha hecho que en todas las instituciones escolares se pregunten por el currículo; sin embargo, ¿para qué educamos? Tadeu da Silva (1999) propone el currículo como trayectoria, viaje, recorrido, autobiografía, pues el currículum se forja como discurso. Tendremos entonces que buscar las huellas del currículo para reconocer cómo este se llena de nuevos sentidos y significados en este nuevo escenario. Pero ¿por qué estos meses han generado 
esa sensación de extrañamiento? Quizá porque muchas prácticas que teníamos instauradas se han modificado. Como lo señala Plut (2020), en todas esas prácticas surge una dimensión de algo que es extraño, ajeno. En ese sentido, ¿cuál es la dimensión de lo nuevo en estas prácticas? Posiblemente está relacionado con que todos estamos viviendo emociones comunes, distintos afectos nos atraviesan: miedo, incertidumbre, aburrimiento, tristeza. "Los afectos que sentimos corresponden a la intimidad de cada quien, son un núcleo arraigado de nuestra subjetividad" (Plut, 2020, p. 14). Y ¿de qué manera las instituciones escolares les abren un lugar?, ¿cómo acoger lo que pasa?

Si las emociones atraviesan todas las esferas del ser humano y con ellas recorremos los terrenos que transitamos, es porque estamos llenos de afectos pero, como lo señala Freud (1976), los afectos tienen efectos sobre el pensamiento y surgen a través de representaciones que se dan en las palabras. Por eso es tan importante recuperar la palabra en las aulas, dado que es la clave para enfrentar la vulnerabilidad y la angustia que genera una situación traumática. No para encontrar sentido, sino para que, frente a emociones como la angustia, las exigencias de la escuela, el agobio o la saturación de información, los estudiantes puedan reconocer que no están solos, que no están sometidos ni tomados por algo ajeno, que no están arrinconados, de tal manera que recobren su voz y su lugar como sujetos activos. En fin, dar la palabra permite reconocer el porqué dicha situación está desprovista de sentido y de qué manera la palabra nos recupera, nos proporciona esperanza.

Es precisamente allí, desde las palabras, donde docentes y estudiantes podemos superar esta situación inédita. Las palabras advierten nuevos caminos para superar la angustia y devolver la condición de sujetos; aparecen y permiten construir nuevos límites en los discursos que construimos sobre nuestros afectos y sus efectos como un nuevo lugar para reconocer nuestras emociones. Una vez más, desde este viaje que atravesamos, reconocemos cómo la reflexión sobre la pandemia y la educación debe considerar, además de la construcción de conocimientos disciplinares, el que estos no puedan estar separados de la experiencia que estamos viviendo, para no quedar condenados al silencio, pues el lenguaje y las palabras que los componen son memoria de nuestras experiencias. En este sentido, Popper (1972, p. 261) señala que "las palabras son los anteojos, y también los ojos de los que pensamos".

\section{A manera de cierre}

De Sousa (2020) recuerda cómo "la crisis es, por naturaleza, excepcional y temporal, y constituye una oportunidad de superación para originar un mejor estado de cosas" (p. 20). Toda crisis trae consigo la oportunidad de la renovación. Esperamos que todos aquellos que estén interesados por mejorar sus prácticas de enseñanza y de aprendizaje en tiempos de pandemia se pregunten no solamente qué, cómo y para qué enseñar, sino que allí aparezcan algunas reflexiones en torno a la importancia del cuerpo, las emociones y las palabras. El medio ambiente, el cuerpo y sus experiencias emocionales, perceptivas y motoras, son elementos importantes para el desarrollo de los procesos cognitivos de nuestra especie. Como afirma Maturana (2001):

Lo humano se constituye en el entrelazamiento de lo emocional con lo racional [...] Corrientemente vivimos nuestros argumentos racionales sin hacer referencia a las emociones en que se fundan, porque no sabemos que ellos y todas nuestras acciones tienen un fundamento emocional, y creemos que tal condición sería una limitación a nuestro ser racional. (p. 8)

De acuerdo con lo anterior, uno de los efectos potenciales sobre la sociedad será la comprensión de las emociones y su importancia en el escenario educativo. 
En ese sentido, abrir las puertas de las instituciones educativas para llenar de palabras los pensamientos y los afectos puede constituirse en una oportunidad para reconocer lo invisible, lo ajeno, y poder representarlo con palabras, para recuperar los lazos rotos que revelan de dónde vienen esos afectos y cómo la humanidad no se deja arrinconar por ellos. Entonces advertimos que algo de lo perdido se puede recuperar la apertura de las puertas del aula al habla, pues es desde allí que se puede dar lugar nuevamente a nuestra voz, para que desde estos espacios los maestros podamos acoger lo que les pasa a los actores educativos.

\section{Referencias bibliográficas}

Da Silva, T. (1999). Documentos de identidad. Una introducción a las teorias del currículum. Auténtica: Belo Horizonte.

De Sousa Santos, B. (2020). La cruel pedagogía del virus. Buenos Aires: Biblioteca Masa Crítica Clacso.
Freud, S. (1976). Obras completas 1925-1926. Argentina: Amorrotu Editores.

Gallese, V., Fadiga, L., Fogassi, L. y Rizzolatti, G. (1996). Action recognition in the premotor cortex. Brain, 119, 593-609.

Maturana, H. (2001). Emociones y lenguaje en educación y política. Santiago de Chile: Ediciones Dolmen.

McNeill, D. (1992). Hand and mind. Chicago: University of Chicago Press.

Merleau-Ponty, M. (1975). Fenomenología de la percepción. Trad. Jem Cabanes. Barcelona: Ediciones Península.

Piaget, J. (1999). La psicología de la inteligencia. Barcelona: Editorial Crítica.

Plut, S. (2020). Los coronautas, pánico colectivo y sufrimiento psíquico. Buenos Aires: Ricardo Vergara Ediciones.

Popper, K. R. (1972). Evolution and the tree of knowledge. En Objetive Knowledge, An Evolutionary Approach (pp. 256-284). Oxford: Claredon Press.

Varela, F., Thompson, E. y Rosch, E. (1993). The embodied mind: cognitive science and human experience. Cambridge: The MIT Press. 